RESEARCH PAPER

\title{
Households contaminated by environmental tobacco smoke: sources of infant exposures
}

\author{
G E Matt, P J E Quintana, M F Hovell, J T Bernert, S Song, N Novianti, T Juarez, J Floro, \\ C Gehrman, M Garcia, $S$ Larson
}

Tobacco Control 2004;13:29-37. doi: 10.1136/tc.2003.003889

See end of article for authors' affiliations

Correspondence to: GE Matt, PhD, Department of Psychology, San Diego State University, San

Diego, CA 92182-4611, USA; gmatt@sciences. sdsu.edu

Received 12 March 2003 Accepted 2 October 2003
Objectives: To examine (1) whether dust and surfaces in households of smokers are contaminated with environmental tobacco smoke (ETS); (2) whether smoking parents can protect their infants by smoking outside and away from the infant; and (3) whether contaminated dust, surfaces, and air contribute to ETS exposure in infants.

Design: Quasi-experiment comparing three types of households with infants: (1) non-smokers who believe they have protected their children from ETS; (2) smokers who believe they have protected their children from ETS; (3) smokers who expose their children to ETS.

Setting: Homes of smokers and non-smokers.

Participants: Smoking and non-smoking mothers and their infants $\leqslant 1$ year.

Main outcome measures: ETS contamination as measured by nicotine in household dust, indoor air, and household surfaces. ETS exposure as measured by cotinine levels in infant urine.

Results: ETS contamination and ETS exposure were 5-7 times higher in households of smokers trying to protect their infants by smoking outdoors than in households of non-smokers. ETS contamination and exposure were 3-8 times higher in households of smokers who exposed their infants to ETS by smoking indoors than in households of smokers trying to protect their children by smoking outdoors.

Conclusions: Dust and surfaces in homes of smokers are contaminated with ETS. Infants of smokers are at risk of ETS exposure in their homes through dust, surfaces, and air. Smoking outside the home and away from the infant reduces but does not completely protect a smoker's home from ETS contamination and a smoker's infant from ETS exposure.
$\mathrm{E}$ nvironmental tobacco smoke (ETS)-also known as secondhand smoke-is a complex mixture of more than 4000 chemical compounds that are generated during the burning of tobacco products. This mixture contains numerous irritants and toxicants with acute health effects as well as toxicants with carcinogenic effects in humans. ETS is known to increase morbidity and mortality risks in infants, children, and adult non-smokers. ${ }^{1-4}$

Data from the California Tobacco Survey (CTS) indicate that, in 1999, $72.8 \%$ of homes in California were smoke-free, leaving approximately one in four homes at risk of contributing to tobacco exposure of non-smokers. ${ }^{5}$ In homes with children under 6 years of age where all adults smoked, $56.7 \%$ of respondents reported having a complete smoking ban. In homes with children where only some adults smoked, $73.1 \%$ were reportedly smoke-free in 1999. A similar picture emerges for the USA at large. Data from the National Health and Nutrition Examination Survey III show that $43 \%$ of US children (aged 2 months to 11 years) lived in a home with at least one smoker, and that $37 \%$ of adult non-tobacco users lived in a home with a smoker or reported exposure to ETS at work. $^{67}$ More recently, the 2000 Behavioral Risk Factor Surveillance System collected data from 20 states about smoking policies at home. The percentage of adults reporting no smoking at home ranged from $61 \%$ (Virginia) to $79 \%$ (Colorado), ${ }^{7}$ suggesting that $20-40 \%$ of US homes contribute to tobacco exposure of non-smokers.

The best understood route of exposure to ETS is the inhalation of contaminated indoor air. ${ }^{12}$ In addition to gas and vapour phase ETS components, contaminated air also contains ETS particles. Because the ETS particles have a mass median aerodynamic diameter of well below $2.5 \mu \mathrm{m},{ }^{8}$ they become respirable suspended particles (RSPs) that cannot be easily filtered and removed by the protective mechanisms of nose and throat. The size of these particles allows them to enter the deep lung and to cause damage due to their size alone. ${ }^{9}$ To this effect can be added the chemical toxicity of the particles that enter the deep lung. Thus, both the size of ETS particles and the systemic effects of the chemical toxicity of ETS components may contribute to morbidity.

Inhaling ETS while a cigarette is being smoked is the most noticeable, though not the only exposure occasion. From ETS chamber and field studies, it is known that ETS components are rapidly dispersed after emission and undergo further dynamic chemical reactions. ${ }^{8}$ Vapour phase components deposit and are adsorbed onto walls, furniture, clothes, toys, and other objects within 10 of minutes to hours after tobacco smoke has been emitted. From there, they are re-emitted into the air over the course of hours to months. ETS particulate matter can deposit on surfaces within hours after smoking occurred, from where it may be re-suspended or react with vapour phase compounds. Through this dynamic behaviour, ETS can contaminate house dust, carpets, walls, furniture, and other household objects for weeks and months after ETS was emitted from a cigarette. Findings from controlled chamber and field studies suggest that residential indoor

Abbreviations: CDC, US Centers for Disease Control and Prevention; CTS, California Tobacco Survey; DEG, direct exposure group; ETS, environmental tobacco smoke; IEG, indirect exposure group; NEG, no exposure group; PAH, polycyclic aromatic hydrocarbons; PPM, Pearson product moment; RSP, respirable suspended particles; WIC, Women, Infants, and Children Supplemental Food and Nutrition Program 
environments become reservoirs for ETS, turning contaminated dust, carpets, and other household objects into potential sources of ETS exposure long after smoking has stopped. $^{8}{ }^{10}$

Infants of smoking parents are at a particular risk of secondhand smoke exposure through contaminated house dust and surfaces. During their first year of life, infants spend much time indoors, are in close proximity to contaminated dust and objects (for example, blankets, carpets, floors), and are in close physical contact with their smoking parents. At approximately $0.05-0.25 \mathrm{~g} / \mathrm{day}$, the dust ingestion rate in infants is estimated to be more than twice that of adults. ${ }^{11}$ Moreover, because of their developmental stage, infants exhibit a much higher frequency of hand-to-mouth and object-to-mouth contacts and ingestion of non-food items (that is, pica behaviour) than older children or adults. ${ }^{12}$ In addition to increased inhalation of contaminated dust, infants may also be exposed to ETS through ingesting and touching contaminated objects and surfaces. As infants and young children are highly active near the floor, they may also be exposed to higher levels of re-suspended floor dust than adults.

House dust and contaminated surfaces are known to be a major source of contaminants such as lead, allergens, pesticides, and polycyclic aromatic hydrocarbons (PAH). ${ }^{11}$ However, little research is available on ETS contamination of house dust. Hein et $a l^{13}$ were the first to detect nicotine in house dust from homes of smokers. They compared house dust from homes of 34 smokers and 38 non-smokers and found a strong positive correlation $(r=0.65)$ between amount smoked and the nicotine concentration in the house dust. The amount of nicotine inhaled during one hour was estimated for someone in a home with high nicotine concentration in the house dust to be $12 \mathrm{ng}$, a relatively small amount compared to that inhaled by an active smoker (600-3000 ng/h). However, considering that an infant may spend the entire day indoors, has a higher respiration rate (factor 3-8) and a lower body weight than an adult (factor 10-20), this relatively low dosage of ETS exposure may accumulate over the course of weeks to levels equivalent to several hours of active adult smoking. Thus, long term exposure to contaminated house dust raises the possibility of significant exposure to toxic agents in ETS, which might contribute to disease aetiology or exacerbation of pre-existing illness.

This study explored the potential role of dust and surface contamination as sources of exposure to the contents of ETS for infants. We compared three types of households. The "direct exposure group" (DEG) consisted of households in which parents smoked indoors at home and in the presence of their child. The "indirect exposure group" (IEG) consisted of households in which parents smoked and attempted to protect their infants by smoking outside of the home and in the absence of their child. The control group ("no exposure group", NEG) consisted of households with parents who have never smoked, in which no smoking took place indoors, and the infant was not knowingly exposed to tobacco smoke elsewhere. Multiple measures of air, dust, and surface contamination and multiple measures of the infants' exposure to tobacco smoke were examined to address the following questions:

- Are house dust and surfaces in households of smokers contaminated with secondhand smoke?

- Do smoking parents protect their infants by smoking outside and away from the infant?

- Do contaminated household dust and surfaces contribute to the overall exposure of infants to secondhand smoke?

\section{METHODS}

\section{Participants}

Participants were recruited through advertisement at WIC (Women, Infants, and Children Supplemental Food and Nutrition Program; 96\%) sites in San Diego County and in the local news media (4\%). Interested mothers were contacted by phone to determine their eligibility. To qualify, all mothers had to have an infant between 2-12 months old and could not have breast fed their baby within the past 30 days. Though we understand that breast feeding may enhance the health of an infant, we elected to omit families where the mother was breastfeeding the infant because breastfeeding by a smoker (or mother exposed to ETS) may transmit nicotine and confound our cotinine measures of ETS. Subjects were paid up to $\$ 100$ for participating in the study. Forty nine infants aged 2-13 months and their mothers completed the study.

Table 1 provides sociodemographic information about the household, mothers, and infants in the three exposure groups. The three groups did not differ (all p >0.15) with respect to household size and income, size of the home, age and sex of the infant, and mother's age and employment status. Mothers in the non-exposure group tended to be more educated (35\% completed college) than mothers in the indirect $(6 \%)$ and direct $(0 \%)$ exposure groups $\left(\chi^{2}(2)=11.0, p=0.004\right)$. Moreover, the proportion of white non-Hispanic mothers was lower in the NEG (41\%) than the IEG (69\%) and DEG $(75 \%)$ households, although this difference was not significant $\left(\chi^{2}(2)=4.5\right.$, $\mathrm{p}=0.103)$.

\section{Design and setting}

This study relied on a non-equivalent group design, comparing three types of households in which infants were not exposed, indirectly exposed, or directly exposed to tobacco smoke. To qualify for the no exposure control group (NEG), all of the following conditions had to be met at the time of screening: (1) all household residents were non-smokers (that is, consumed no tobacco products) for at least one year; (2) no regular visitors smoked in the residence during the last year; (3) no visitors (regular or occasional) smoked cigarettes in the residence within the past 30 days; (4) there were no visits to a home where someone smoked in the same room with the infant within the past 30 days. In summary, NEG households $(n=17)$ serve as the baseline for ETS contamination and exposure measures.

To qualify for the indirect exposure group (IEG), all of the following conditions had to be met: (1) the mother had to smoke every day and at least 20 cigarettes/week over the past three months; (2) the mother or other household residents may not have smoked any cigarettes in the same room (or car) with the infant over the past three months; (3) the mother must have smoked at least 10 cigarettes/week at home outside or in a different room from the infant over the past three months. To rule out that smoking indoors at home in a different room contributed to direct ETS exposure, we identified households in which reportedly no indoor smoking took place during the assessment period. Findings are reported separately for all IEG households and those without indoor smoking. In summary, IEG households $(n=17)$ represent smoking parents who have made serious attempts to protect their children from ETS by not smoking in their presence. This group comes closest to what are commonly referred to as households with smoking bans. ${ }^{5}$

To qualify for the direct exposure group (DEG) all of the following conditions had to be met: (1) the mother had to smoke every day and at least 20 cigarettes/week over the past three months; (2) the mother or other household residents must have smoked at least 20 cigarettes per week at home 
Table 1 Demographic characteristics of participants in different exposure groups

\begin{tabular}{|c|c|c|c|}
\hline Demographic characteristics & $\begin{array}{l}\text { No } \\
\text { exposure }\end{array}$ & $\begin{array}{l}\text { Indirect } \\
\text { exposure }\end{array}$ & $\begin{array}{l}\text { Direct } \\
\text { exposure }\end{array}$ \\
\hline $\begin{array}{l}\text { Sample size } \\
\text { Infant }\end{array}$ & 17 & 17 & 15 \\
\hline Female (\%) & 59 & 56 & 47 \\
\hline Mean age (months) & 7.6 & 6.1 & 7.7 \\
\hline \multicolumn{4}{|l|}{ Race/ethnicity (\%) } \\
\hline African American & 18 & 6 & 19 \\
\hline White non-Hispanic & 29 & 69 & 63 \\
\hline Mexican American & 12 & 0 & 6 \\
\hline Multiracial & 29 & 0 & 13 \\
\hline Other & 6 & 19 & 0 \\
\hline \multicolumn{4}{|l|}{ Mother } \\
\hline \multicolumn{4}{|l|}{ Race/ethnicity (\%) } \\
\hline African American & 18 & 6 & 13 \\
\hline White non-Hispanic & 41 & 69 & 75 \\
\hline Mexican American & 18 & 0 & 0 \\
\hline Multiracial & 12 & 0 & 6 \\
\hline Other & 12 & 25 & 6 \\
\hline \multicolumn{4}{|l|}{ Education level* } \\
\hline Did not complete high school & 18 & 0 & 13 \\
\hline Completed high school & 12 & 44 & 44 \\
\hline Technical/vocational school & 0 & 6 & 25 \\
\hline Some college & 41 & 44 & 19 \\
\hline Completed college & 35 & 6 & 0 \\
\hline \multicolumn{4}{|l|}{ Employment status } \\
\hline Not employed & 71 & 81 & 56 \\
\hline Part time $(<40$ hours & 12 & 6 & 25 \\
\hline full-time ( $\geqslant 40$ hours) & 19 & 13 & 19 \\
\hline \multicolumn{4}{|l|}{ Household } \\
\hline Total income (median) & $\$ 24000$ & $\$ 21000$ & $\$ 25000$ \\
\hline $\begin{array}{l}\text { Size of residence (median, } \\
\text { square feet) }\end{array}$ & 639 & 586 & 736 \\
\hline Number residents (median) & 4 & 4.5 & 4 \\
\hline
\end{tabular}

over the past three months; (3) the mother or other household residents had to smoke one or more cigarettes per day (or seven cigarettes per week) at home in the same room with the infant. In summary, DEG households $(\mathrm{n}=15)$ represent smoking parents without a smoking ban at home who do not systematically attempt to protect their children from tobacco smoke.

\section{Measures}

\section{Measurement schedule}

Each residence was visited three times over the course of one week. All visits took place on a Tuesday, Friday, Monday schedule or a Friday, Monday, and Thursday schedule, such that all measures included exposures during a weekend. Each visit consisted of an interview with the mother, the collection of dust and surface wipe samples in the living room and the infant's bedroom, the collection of a urine sample from the infant, and the collection of a wipe sample from the mother's index finger of her dominant hand. Air nicotine monitors were placed in the living room and the infant's bedroom at the first visit and collected for analyses at the third visit. A hair sample was obtained from the infant at the third visit.

\section{Face-to-face interview}

At the first visit, a face-to-face interview was conducted with the mother about: (a) the mother's sociodemographic background; (b) household composition; (c) home characteristics, including type of home, size, pets, and furnishing; (d) cleaning activities over the past 30 days; (e) typical infant activities, schedule, and mouthing behaviours; (f) mother's smoking history; (g) smoking behaviour of the mother and other household residents over the past three days; (h) infant's exposure to secondhand smoke over the past three days. Parts ( $\mathrm{g}$ ) and (h) of the interview were repeated at the second and third visit. Based on these interviews, the following reported measures were determined: (1) mother's average number of cigarettes smoked per day; (2) the average number of cigarettes per day to which the infant was exposed; and (3) the total number of cigarettes to which the infant was exposed (that is, cigarettes smoked in the presence of the infant). All interview measures reflect behaviours over a 10 day period, consisting of seven study days plus the three days preceding the first visit. Matt et al ${ }^{14} 15$ present relevant findings on the reliability and validity of parent reported secondhand smoke exposure.

\section{Behaviour diary}

At the first and second visit, the mother was given a diary, and she was instructed to record until the next visit the child's whereabouts, activities, presence of smokers, exposure to tobacco smoke, and mother's smoking. Based on these diaries, the following additional reported measures were determined: (4) average number of cigarettes per day smoked indoors by the mother, other household residents, and visitors; (5) mother's average number of cigarettes smoked per day; (6) total number of cigarettes to which the infant was exposed; and (7) average number of cigarettes per day to which the infant was exposed. All diary based measures reflect behaviours over the seven study days only. The interview (1), (2), and (3) and diary based measures (5), (6), and (7) assessed the same behaviours over slightly different reference periods. Thus, they served as a check for consistency between retrospective reported behaviour and prospectively recorded practices, but they could not be compared directly because they represented slightly different time frames.

\section{Air nicotine in living room and bedroom}

Air levels of vapour phase nicotine were measured with passive diffusion monitor badges developed by Hammond et $a l^{16}$ and used by us previously. ${ }^{15}{ }^{17}$ The badges were placed in the baby's home for the duration of the week, placed on the first and removed on the third visit. One badge was placed in the living area and one in the baby's sleeping area. The height of the monitors was 2 feet from the floor, and badges were placed away from doors and windows. Unmarked non-analysed badges were placed in all other rooms such that all rooms appeared to have air monitors, in keeping with a bogus pipeline procedure. ${ }^{18}$ This was employed to prevent smokers moving to a room without a monitoring badge. The number of hours placed in the home was recorded. The badges consisted of a modified $37 \mathrm{~mm}$ diffusive sampling cassette with a sodium bisulfate treated Teflon coated glass fibre filter. The badges were stored at $-20^{\circ} \mathrm{C}$ and sent to $\mathrm{K}$ Hammond (University of California, Berkeley) for analysis as previously described. ${ }^{16}$ Briefly, the nicotine was extracted into hexane and analysed on a gas chromatograph with a nitrogen detector, and results expressed as $\mu \mathrm{g}$ of nicotine $/ \mathrm{m}^{3}$ of air. The level of detection for one full week of exposure is $0.02 \mu \mathrm{g} / \mathrm{m}^{3}$.

\section{Dust nicotine in living room and bedroom}

Two area floor dust samples per visit were collected with a high volume, small surface sampler (HVS3, CS-3 Inc, Sandpoint, Idaho, USA), from a $150 \mathrm{~cm} \times 150 \mathrm{~cm}$ area, if possible. Some homes had a smaller area sampled, with none being less than $100 \mathrm{~cm} \times 100 \mathrm{~cm}$. One sample was obtained from the living room area and the other from the infant's sleeping area. Areas were carefully measured from reference points in the home to allow collection of dust from the same area each time, without leaving any marks visible to the occupants. Floor dust samples were collected into Teflon 
bottles, transported cooled, weighed, and sieved with a stainless steel, methanol washed, $150 \mu \mathrm{m}$ mesh sieve. Sieved dust was weighed and stored in glass bottles at $-70^{\circ} \mathrm{C}$ until analysis. Analysis for nicotine was performed on a gas chromatograph equipped with mass spectrometry (GC-MS, HP 6890) using a method adapted from one developed at the US Centers for Disease Control and Prevention (CDC) ${ }^{19}$ for analysis of nicotine in wipe samples. Cotinine and its labelled reference methyl-d3 cotinine were originally included in all analysis, but when approximately half of the samples had been analysed with cotinine detected in only two, cotinine was dropped from further analysis. The limit of detection was $0.03 \mu \mathrm{g} / \mathrm{mg}$ dust (CDC method) to $0.002 \mu \mathrm{g} / \mathrm{mg}$ dust (SDSU method, J Polansky modifications).

\section{Surface nicotine on furniture in living room and bedroom}

Two area wipe samples per visit were taken with a prescreened wipe, covering a $10 \times 10 \mathrm{~cm}$ area. Wipes were soaked in freshly prepared $0.1 \%(\mathrm{w} / \mathrm{v})$ ascorbic acid to preserve the nicotine. One wipe was taken from the living room area (typically the coffee table). The other wipe was taken from the baby's sleeping area (typically the bed frame). The same locations were wiped each visit. Wipes were placed into glass bottles, transported cooled, and stored at $-70^{\circ} \mathrm{C}$ until analysis. Levels were expressed as weight of nicotine per wipe. The limit of detection was $0.06 \mu \mathrm{g} /$ wipe (CDC) to $0.01 \mu \mathrm{g} /$ wipe (SDSU method, J Polansky modifications).

\section{Nicotine on mother's index finger}

A wipe sample of the mother's index finger from the hand used to hold a cigarette was taken at each visit. Wipe was moistened and processed as above. In order to keep costs down while investigating the hypothesis that some nicotine might be present on mother's hands, only one sample was chosen for analysis from four mothers in the IEG and four mothers in the DEG groups.

\section{Urine cotinine}

Urine samples were collected from the infant at each visit using a standard urine collection bag for infants or a cotton roll placed in the diaper. ${ }^{14}{ }^{15}$ Cotton rolls were placed in a sterile $20 \mathrm{ml}$ syringe and expressed into sterile $5 \mathrm{ml}$ plastic cryovials. Samples were immediately frozen at $-20^{\circ} \mathrm{C}$ before they were packed in dry ice and shipped to the CDC for analysis using high performance liquid chromatography, atmospheric pressure chemical ionisation tandem mass spectrometry (HPLC APCI-MS ${ }^{20}$ ). Cotinine levels reported are "total" cotinine, combining bound and unbound quantities of the metabolite. The assay is sensitive to levels as low as $0.05 \mathrm{ng} / \mathrm{ml}$.

\section{Hair nicotine and cotinine}

In combination with the urine cotinine measure (1-3 days' half life), hair cotinine provides a measure of exposure over a longer period of time (1-2 months). ${ }^{21}{ }^{22}$ Hair samples were obtained at the last visit by cutting $1 \mathrm{~cm}$ of $10-15$ hair shafts (approximately $10 \mathrm{mg}$ in weight) close to the scalp from the back of the head (posterior vertex, occipital bone) using methanol cleaned scissors. Samples were stored in sterile vials and sent to J Klein (University of Toronto) for analysis as described. ${ }^{23}$ The limits of detection were $0.02 \mathrm{ng} / \mathrm{mg}$ and $0.05 \mathrm{ng} / \mathrm{mg}$ for cotinine and nicotine, respectively.

\section{Statistical analyses}

Statistical analyses were conducted using STATA $7.0^{24}$ and SPSS 10.1..$^{25}$ All outcome measures were subjected to logarithmic transformation before analyses were conducted to deal with skewed error distribution and to stabilise error variances. Relations between measures of contamination and exposure were examined using rank order and Pearson product moment (PPM) correlations. Because findings do not differ substantially, we only report those for PPM correlations. Significance was set at $\alpha=0.05$.

Differences in outcome measures between groups were tested via Tobit regression models,$^{26}$ in which an observation was defined as left censored if the value fell below the detection limit of a particular outcome measure. In addition, we used robust estimates of standard errors based on the Huber-White sandwich estimator of variance ${ }^{27}$ to protect against the undue influence of outliers on statistical tests in this relatively small sample.

The contribution of house dust and surface contamination to overall exposure was examined using OLS regression models with robust standard errors based on the HuberWhite sandwich estimator of variance. ${ }^{26} 27$

\section{RESULTS}

\section{Smoking behaviour and smoking policies}

Table 2 presents descriptive information regarding smoking behaviour and smoking policies in the three exposure groups. In NEG households, nobody was a smoker and no smokers had reportedly visited during the 30 days before the interview.

The IEG and DEG households did not differ significantly with respect to the number of smokers and the percentage of visitors smoking outside of the home. Mothers in DEG households smoked more than mothers in IEG households based on interview data $(9.34 v 5.38$ cigs/day $(\mathrm{t}(30)=2.49$, $\mathrm{p}=0.018)$ but not based on diary data $(6.20 \vee 5.41$ cigs/day; $\mathrm{t}(31)=0.44, \mathrm{p}=0.662)$. Moreover, DEG households were more likely than IEG households to have visitors who smoked indoors $\left(66.7 \% \quad v \quad 6.3 ; \chi^{2}(1)=10.2, p<0.01\right)$ during the past 30 days. This difference is also reflected in home policies about smoking. Significantly larger proportions of IEG households declared that smokers at home always or almost always smoked outside $\left(88 \% \vee 27 \% ; \chi^{2}(2)=9.3\right.$, $\mathrm{p}<0.01)$ and shut the doors or windows when smoking outside $\left(69 \%\right.$ v 13\%; $\left.\chi^{2}(2)=13.6, \mathrm{p}<0.01\right)$.

In the IEG households, all mothers were smokers and about two out of three households had one or more additional smokers. Four of the 17 IEG households reported that cigarettes were smoked in the home, for an average of $1.06 \mathrm{cigs} /$ day in these four households. Three of these four households also reported that their infants were in a room or car where cigarettes were smoked at home or away from home. In the three households where this occurred, the infants were directly exposed to an average of $0.38 \mathrm{cigs} /$ day.

To control for the occasional indoor exposure of some infants in the IEG group, we identified a subgroup of IEG households in which reportedly no cigarettes were smoked in the home during the assessment week and infants were not knowingly exposed to tobacco smoke (for example, at home, in a car, at someone else's home). This was done to investigate whether smoking indoors during the assessment period contributed to ETS contamination at home and the child's exposure. There were no statistically (all p $>0.20$ ) or practically significant differences on any of the exposure measures between the "no indoor smoking/no direct exposure" IEG subgroup $(\mathrm{n}=12)$ and the "occasional indoor smoking/occasional direct exposure" IEG subgroup $(\mathrm{n}=4)$. Similarly, there were no significant differences between the two IEG subgroups in contamination measures, with the exception of the maximum nicotine loading in living room and bedroom dust (table 3). We also investigated whether excluding the four households with occasional indoor smoking and direct exposure would alter findings concerning group differences between NEG, IEG, and DEG households. 
Table 2 Smoking behaviours in different exposure groups

\begin{tabular}{|c|c|c|c|c|}
\hline \multirow[b]{2}{*}{ Reported smoking behaviour and home policies } & \multirow{2}{*}{$\begin{array}{l}\text { No } \\
\text { exposure }\end{array}$} & \multicolumn{2}{|l|}{ Indirect exposure } & \multirow[b]{2}{*}{ Direct exposure } \\
\hline & & All & No indoor smoking & \\
\hline Sample size & 17 & 17 & 13 & 15 \\
\hline Average number of smokers in household & 0 & 1.69 & 1.75 & 1.93 \\
\hline \multicolumn{5}{|l|}{ Households (\%) with } \\
\hline 0 smokers & 100 & 0 & 0 & 0 \\
\hline 1 smoker & 0 & 43.8 & 41.7 & 33.3 \\
\hline 2 smokers & 0 & 43.8 & 41.7 & 53.3 \\
\hline 3 or more smokers & 0 & 12.5 & 16.7 & 12.4 \\
\hline \multicolumn{5}{|l|}{ Households (\%) in which } \\
\hline Mother smokes & 0 & 100 & 100 & 100 \\
\hline Visitors smoked in home in past 30 days & 0 & 6.3 & 0 & 66.7 \\
\hline Visited someone who smoked in past 30 days & 0 & 93.7 & 33.3 & 40.0 \\
\hline \multicolumn{5}{|l|}{ Households (\%) in which smokers go outside to smoke } \\
\hline Always & & 81.3 & 91.7 & 6.7 \\
\hline Almost always & & 6.3 & 0 & 20.0 \\
\hline Often, sometimes & & 12.5 & 8.3 & 53.3 \\
\hline Rarely, never & & 0 & 0 & 20.0 \\
\hline \multicolumn{5}{|l|}{$\begin{array}{l}\text { Households (\%) with doors/windows shut when } \\
\text { someone smokes outside }\end{array}$} \\
\hline Always & & 50.0 & 66.7 & 6.7 \\
\hline Almost always & & 18.8 & 16.7 & 6.7 \\
\hline Often, sometimes & & 12.5 & 8.3 & 20.0 \\
\hline Rarely, never & & 18.8 & 8.3 & 66.7 \\
\hline \multicolumn{5}{|l|}{ Smoking (geometric mean, $95 \% \mathrm{Cl}$ ) } \\
\hline Mother's average cigs/day (diary 7 days) & 0 & $5.41(3.33$ to 9.49$)$ & 5.20 (2.72 to 9.35$)$ & 6.20 (3.83 to 10.74$)$ \\
\hline Mother's average cigs/day (interview past 10 days) & 0 & $5.38(3.40$ to 8.25$)$ & $4.44(2.45$ to 9.35$)$ & $9.34(7.63$ to 11.40$)$ \\
\hline
\end{tabular}

However, this was not the case. Therefore, all subsequent statistical analyses rely on the entire group of 17 IEG households to maintain sufficient statistical power. In tables 2, 3, and 4, we report separately findings for all 17 IEG households and the subgroup of 12 households without indoor smoking.

\section{Contamination of the indoor home environment}

Table 3 presents the nicotine levels found in the air, in dust, on surfaces, and on fingers in the three exposure groups. To investigate whether contamination levels differed between exposure groups, NEG households were compared to IEG households (contrast 1, Cl) and IEG households were compared to DEG households (contrast 2, C2).

\section{Air nicotine levels}

Nicotine was detected in the living room air and the bedroom air in all smoker households and $97 \%$ of non-smoker households. Air nicotine concentrations in the living rooms and infant bedrooms of IEG households were approximately

Table 3 Geometric means and their 95\% confidence intervals for measures of nicotine contamination in different exposure groups

\begin{tabular}{|c|c|c|c|c|}
\hline \multirow[b]{2}{*}{ Nicotine contamination } & \multirow[b]{2}{*}{ No exposure } & \multicolumn{2}{|l|}{ Indirect exposure } & \multirow[b]{2}{*}{ Direct exposure } \\
\hline & & All & No indoor smoking & \\
\hline \multicolumn{5}{|l|}{ Air $\left(\mu \mathrm{g} / \mathrm{m}^{3}\right)$} \\
\hline Living room $\left(\mathrm{n}^{*}=16,17,15\right)$ & $0.10(0.06$ to 0.15$)$ & $0.32(0.12$ to 0.55$)$ & $0.32(0.08$ to 0.62$)$ & $2.57(1.61$ to 3.89$)$ \\
\hline Bedroom $(n=17,17,15)$ & $0.09(0.04$ to 0.16$)$ & $0.22(0.12$ to 0.37$)$ & $0.23(0.10$ to 0.38$)$ & $1.50(0.82$ to 2.42$)$ \\
\hline$\%$ above LOD & & & & 100 \\
\hline \multicolumn{5}{|l|}{ Surface: living room $\left(\mu \mathrm{g} / \mathrm{m}^{2}\right)$} \\
\hline Maximumt $(n=10,17,15)$ & 0 & $19.89(3.41$ to 38.99$)$ & $20.19(0.00$ to 38.01$)$ & 73.05 (32.09 to 126.71 ) \\
\hline Average $\neq(n=10,17,15)$ & 0 & 10.68 (2.62 to 19.38$)$ & $10.08(0.01$ to 21.10$)$ & $51.33(19.17$ to 32.16$)$ \\
\hline$\%$ above LOD§ & 0 & 51 & 39 & \\
\hline \multicolumn{5}{|l|}{ Surface: bedroom $\left(\mu \mathrm{g} / \mathrm{m}^{2}\right)$} \\
\hline Maximum ${ }^{*}(n \dagger=10,17,15)$ & 0 & 10.82 (5.84 to 16.03$)$ & 9.11 (3.99 to 14.49) & 56.26 (32.24 to 84.64$)$ \\
\hline Average $\neq(n=10,17,15)$ & 0 & $9.00(4.35$ to 13.86$)$ & 8.19 (2.69 to 14.98$)$ & 41.85 (24.71 to 59.09$)$ \\
\hline \multirow{2}{*}{\multicolumn{5}{|c|}{ Index finger ( $\mu \mathrm{g} /$ wipe) }} \\
\hline & & & & \\
\hline Average $(n=3,4,7)$ & 0 & $0.63(0.00$ to 2.4$)$ & $0.62(0.00$ to 5.60$)$ & $0.65(0.16$ to 1.36$)$ \\
\hline$\%$ above $\operatorname{LOD}(\mathrm{n}=3,4,7)$ & 0 & 100 & 100 & 92 \\
\hline \multicolumn{5}{|l|}{ Dust: living room $\left(\mu \mathrm{g} / \mathrm{m}^{2}\right)$} \\
\hline Maximum $(n=0,15,14)$ & NA & 4.43 (1.04 to 18.86$)$ & $2.82(0.00$ to 17.69$)$ & 64.00 (15.51 to 254.93 ) \\
\hline Average $(n=0,15,14)$ & NA & $2.22(0.03$ to 9.01$)$ & $1.82(0.00$ to 8.62$)$ & 6.85 (3.76 to 15.37$)$ \\
\hline$\%$ above LOD & NA & 38 & 35 & 55 \\
\hline \multicolumn{5}{|l|}{ Dust: bedroom $\left(\mu \mathrm{g} / \mathrm{m}^{2}\right)$} \\
\hline Maximum $(n=0,14,13)$ & NA & $3.22(0.00$ to 9.50$)$ & $1.57(0.00$ to 6.91$)$ & 15.84 (4.44 to 51.17 ) \\
\hline Average $(n=0,14,13)$ & NA & $0.89(0.01$ to 2.58$)$ & $0.71(0.00$ to 2.25$)$ & $5.37(1.61$ to 15.53$)$ \\
\hline$\%$ above LOD & NA & 52 & 56 & 70 \\
\hline
\end{tabular}


Table 4 Geometric means and their $95 \%$ confidence intervals for measures of secondhand smoke exposure in different exposure groups

\begin{tabular}{|c|c|c|c|c|}
\hline \multirow[b]{2}{*}{ Secondhand smoke exposure } & \multirow[b]{2}{*}{ No exposure } & \multicolumn{2}{|l|}{ Indirect exposure } & \multirow[b]{2}{*}{ Direct exposure } \\
\hline & & All & No indoor smoking & \\
\hline \multicolumn{5}{|l|}{ Mother reported infant exposure } \\
\hline Sample size & 17 & 17 & 13 & 15 \\
\hline Average cigs/day (interview 10 days) & 0 & $0.03(0$ to 0.11$)$ & 0 & 5.57 (3.55 to 8.49$)$ \\
\hline Average cigs/day (diary 7 days) & 0 & $0.06(0$ to 0.19$)$ & 0 & 5.75 (3.44 to 9.27 ) \\
\hline \multicolumn{5}{|l|}{ Infant urine cotinine $(\mathrm{ng} / \mathrm{ml}$ ) } \\
\hline Day $1(\mathrm{n} \dagger=15,17,14)$ & 0.30 (0.18 to 0.44$)$ & 2.09 (1.21 to 3.31$)$ & 2.18 (1.21 to 3.58$)$ & 13.13 (8.09 to 20.97$)$ \\
\hline Day $4(n=14,16,14)$ & $0.41(0.21$ to 0.65$)$ & 2.38 (1.50 to 3.57$)$ & $2.15(1.21$ to 3.49$)$ & 17.03 (9.65 to 28.73$)$ \\
\hline Day $7(n=11,12,14)$ & $0.32(0.19$ to 0.47$)$ & 2.88 (1.22 to 5.79$)$ & $2.96(0.69$ to 8.24$)$ & $13.02(8.01$ to 20.81 ) \\
\hline Maximum $(n=16,17,16)$ & $0.43(0.25$ to 0.63$)$ & 3.49 (2.05 to 5.61$)$ & $3.14(1.59$ to 5.60$)$ & $20.43(12.65$ to 32.65$)$ \\
\hline Average $(n=16,17,16)$ & $0.33(0.20$ to 0.46$)$ & 2.47 (1.52 to 3.78$)$ & 2.32 (1.22 to 3.97$)$ & $15.47(10.10$ to 23.44$)$ \\
\hline$\%$ above LOD* & 98 & 100 & 100 & 100 \\
\hline \multicolumn{5}{|l|}{ Infant hair nicotine (ng/mg) } \\
\hline Day $7(n=14,10,13)$ & $0.53(0.25$ to 0.86$)$ & 2.65 (1.10 to 5.34$)$ & $2.75(0.82$ to 6.75$)$ & 5.95 (3.25 to 10.37$)$ \\
\hline \% above LOD & 93 & 100 & 100 & 100 \\
\hline \multicolumn{5}{|l|}{ Infant hair cotinine ( $\mathrm{ng} / \mathrm{mg}$ ) } \\
\hline Day $7(n=14,10,13)$ & $0.08(0.05$ to 0.11$)$ & $0.52(0.20$ to 0.92$)$ & $0.49(0.10$ to 1.03$)$ & 1.05 (0.55 to 1.72$)$ \\
\hline$\%$ above LOD & 93 & 100 & 100 & 100 \\
\hline
\end{tabular}

*Percentage of samples with cotinine levels above the level of detection.

†Sample sizes for no exposure (NEG), all indirect exposure (IEG), and direct exposure (DEG) households

three and two times higher, respectively, than those found in the living and bedroom of NEG households $\left(0.32 \mu \mathrm{g} / \mathrm{m}^{3} v\right.$ $\left.0.10 \mu \mathrm{g} / \mathrm{m}^{3} ; 0.22 \mu \mathrm{g} / \mathrm{m}^{3} v 0.09 \mu \mathrm{g} / \mathrm{m}^{3}\right)$. Air nicotine levels in living rooms and infant bedrooms of DEG households were eight times and seven times higher than in IEG households $\left(2.57 \mu \mathrm{g} / \mathrm{m}^{3}\right.$ v $\left.0.32 \mu \mathrm{g} / \mathrm{m}^{3} ; 1.50 \mu \mathrm{g} / \mathrm{m}^{3} v 0.22 \mu \mathrm{g} / \mathrm{m}^{3}\right)$.

Significant differences were found in air nicotine levels between NEG and IEG (C1) and between IEG and DEG (C2) in the living room (that is, $\chi^{2}(2)=38.75, \mathrm{p}<0.001 ; \mathrm{Cl}$ : $\mathrm{t}(46)=6.19, \mathrm{p}<0.001 ; \mathrm{C} 2: \mathrm{t}(46)=9.69, \mathrm{p}<0.001)$ and bedrooms (that is, $\chi^{2}(2)=38.75, \mathrm{p}<0.001$; $\mathrm{Cl}$ : $\mathrm{t}(46)=4.77, \mathrm{p}<0.001 ; \mathrm{C} 2: \mathrm{t}(46)=7.62, \mathrm{p}<0.001)$. These findings suggest that while parents in the IEG were able to reduce air nicotine levels compared to DEG households, their children were not protected from exposure to nicotine in the indoor air at home.

\section{Surface nicotine levels}

No nicotine was detected on surfaces examined in the living room and infant bedrooms of NEG households. In IEG households, $51 \%$ and $53 \%$ revealed nicotine levels above the limit of detection on living room and bedroom surfaces, respectively. The average level of the highest nicotine level per household was $19.89 \mu \mathrm{g} / \mathrm{m}^{2}$; the average of the mean nicotine level per household was $10.68 \mu \mathrm{g} / \mathrm{m}^{2}$.

Nicotine was detected on $88 \%$ (49 of 56 samples) of the living room and $88 \%$ (35 of 40 samples) of bedroom surfaces in DEG households. Nicotine contamination of surfaces in DEG households was three to five times higher than those found in IEG households. On living room and bedroom surfaces, the average of the highest nicotine levels per household were $73.05 \mu \mathrm{g} / \mathrm{m}^{2}$ and $56.26 \mu \mathrm{g} / \mathrm{m}^{2}$, respectively. The average levels of the mean nicotine level per household were $51.33 \mu \mathrm{g} / \mathrm{m}^{2}$ and $41.85 \mu \mathrm{g} / \mathrm{m}^{2}$ in the living room and bedroom, respectively.

Tobit regression analyses showed significant differences between IEG and DEG households for surface nicotine levels in the living rooms (that is, $\chi^{2}(1)=9.50, p=0.002$; C2: $\mathrm{t}(30)=3.21, \mathrm{p}=0.003$ ) and bedrooms (that is, $\left.\chi^{2}(1)=16.29, \mathrm{p}=<0.001 ; \mathrm{C} 2: \mathrm{t}(30)=4.59, \mathrm{p}<0.001\right)$. These findings suggest that IEG households had lower nicotine levels on household surfaces compared to DEG households. However, IEG households showed surface contamination significantly higher than zero (see confidence interval in table 3). Wipe samples collected in NEG households revealed no detectable levels of nicotine and had to be excluded from the analyses.

\section{Nicotine on fingers}

No nicotine was detected on the fingers of mothers in the NEG households. However, nicotine was detected on the fingers of $100 \%$ and $92 \%$ of mothers in the IEG and DEG households, respectively. The average nicotine levels in both groups were $0.63 \mu \mathrm{g} /$ wipe and $0.65 \mu \mathrm{g} /$ wipe in the IEG and DEG, respectively. Given the surface area of a typical index finger $\left(<100 \mathrm{~cm}^{2}\right)$, the average nicotine loading on the fingers of the smoking mothers in the IEG and DEG households is more than twice as high as the nicotine loading on living room surfaces of DEG households. Note that the confidence intervals are noticeably large because of the small sample sizes.

Tobit regression analyses revealed that nicotine levels found on the index fingers of smoking mothers were significantly larger than zero $(\mathrm{t}(9)=2.63, \mathrm{p}=0.025)$. Controlling for smoking frequency, no significant differences were found in finger nicotine between mothers in the IEG and DEG groups (that is, $\chi^{2}(2)=0.06, p=0.97 ; \mathrm{C} 2$ : $\mathrm{t}(10)=0.13, \mathrm{p}=0.90)$.

\section{Nicotine in household dust}

Approximately equal amounts of dust were found in bedrooms and living rooms of IEG and DEG households. On day 1 of dust collection, $1.50 \mathrm{~g}$ (95\% CI 0.75 to $2.58 \mathrm{~g}$ ) and $1.21 \mathrm{~g}$ ( $95 \%$ CI 0.61 to $2.04 \mathrm{~g}$ ) were collected in the living rooms and bedrooms of IEG households, and $1.50 \mathrm{~g}$, (95\% CI 0.57 to 2.98 ) and $1.57 \mathrm{~g}$ (95\% CI 0.72 to 2.82 ) in the DEG households. Summed across all three dust collections, $3.83 \mathrm{~g}(95 \%$ CI 1.82 to $7.28 \mathrm{~g}$ ) and $2.42 \mathrm{~g}$ ( $95 \%$ CI 1.07 to $4.67 \mathrm{~g})$ were collected in the living rooms and bedrooms of IEG households and $3.07 \mathrm{~g}$ (95\% CI 1.34 to $6.09 \mathrm{~g}$ ) and $2.87 \mathrm{~g}$ (95\% CI 1.50 to $4.99 \mathrm{~g}$ ) in the DEG households.

Nicotine was detected in $38 \%$ and $52 \%$ of dust samples taken from the living rooms and bedrooms of IEG households. The averages of highest nicotine levels found in the living rooms and bedrooms of each household were $4.43 \mu \mathrm{g}$ / $\mathrm{m}^{2}$ and $3.22 \mu \mathrm{g} / \mathrm{m}^{2}$, respectively. The averages of the mean nicotine levels per household were $2.22 \mu \mathrm{g} / \mathrm{m}^{2}$ and $0.89 \mu \mathrm{g} /$ $\mathrm{m}^{2}$ for the living rooms and infant bedrooms, respectively.

Nicotine was detected in $55 \%$ and $70 \%$ of dust samples taken from the living rooms and bedrooms of DEG 
households. The averages of highest nicotine levels found in the living rooms and bedrooms of each household were $64.0 \mu \mathrm{g} / \mathrm{m}^{2}$ and $15.8 \mu \mathrm{g} / \mathrm{m}^{2}$, respectively. The averages of the mean nicotine levels per household were $6.85 \mu \mathrm{g} / \mathrm{m}^{2}$ and $5.37 \mu \mathrm{g} / \mathrm{m}^{2}$ for the living rooms and infant bedrooms, respectively.

Tobit regression analyses revealed significant differences between dust nicotine levels in the living rooms (that is, $\left.\chi^{2}(1)=5.37, \mathrm{p}=0.02 ; \mathrm{C} 2: \mathrm{t}(27)=2.17, \mathrm{p}=0.04\right)$ and bedrooms of IEG and DEG households (that is, $\left.\chi^{2}(1)=5.48, \quad \mathrm{p}=0.02 ; \quad \mathrm{C} 2: \mathrm{t}(27)=2.29, \mathrm{p}=0.03\right)$. These findings suggest that IEG households had lower dust nicotine levels compared to DEG households. Note that dust samples were analysed from IEG and DEG households only, because pilot data revealed no detectable nicotine levels in nonsmoking household.

\section{Infant exposure to tobacco \\ Mother reported exposure}

Mothers in the NEG households reported that their infants were not exposed tobacco smoke either at home or away from home. In the IEG group, $76 \%$ of mothers indicated their child was not exposed to tobacco smoke, and $24 \%$ reported exposure to tobacco smoke away outside of the home (for example, car, friend's home). All mothers in the DEG group reported that their child was exposed to tobacco at home as well as away from home. As indicated by the number of cigarettes smoked in the presence of the child per day, infants in IEG households were directly exposed to 0.03 and 0.06 cigs/day according to the interview and behavioural diary, respectively. Infants in the DEG households were directly exposed to 5.57 and 5.75 cigs/day based on interview and diary reports, respectively.

Tobit regression models indicated that mother reported exposure levels in the IEG group were not significantly larger than zero $(\mathrm{t}(28)=1.75, \mathrm{p}=0.091)$, indicating that mothers noticed little if any ETS exposure. Infant exposure as reported by mothers differed significantly between IEG and DEG households (that is, $\chi^{2}(1)=14.18, p \leqslant 0.001$; $C 2$ : $\mathrm{t}(28)=3.79, \mathrm{p}=0.001)$, indicating that smoking in the presence of the child was substantially higher in DEG than in IEG households.

\section{Urine cotinine}

In the NEG households, infant urine cotinine levels averaged $0.33 \mathrm{ng} / \mathrm{ml}$ and $0.43 \mathrm{ng} / \mathrm{ml}$ based on the mean and the maximum over the three sample days. Urine cotinine levels of infants in the IEG households were approximately eight times higher based on the average $(2.47 \mathrm{ng} / \mathrm{ml})$ and the maximum $(3.49 \mathrm{ng} / \mathrm{ml})$ over the three sample days. Compared to the IEG households, urine cotinine levels in the DEG households were more than six times higher. The mean levels were $15.47 \mathrm{ng} / \mathrm{ml}$ and $20.43 \mathrm{ng} / \mathrm{ml}$ based on the average and the maximum across the three sample days, respectively.

Tobit regression analyses showed significant differences in infant urine cotinine levels between NEG and IEG $(\mathrm{Cl})$ and between IEG and DEG (C2) (that is, $\chi^{2}(2)=76.22$, $\mathrm{p}<0.001 ; \mathrm{Cl}: \mathrm{t}(45)=10.85, \mathrm{p}<0.001 ; \mathrm{C} 2: \mathrm{t}(45)=$ 12.76, $\mathrm{p}<0.001)$. Moreover, urine cotinine levels in the IEG differed significantly from zero $(\mathrm{t}(45)=19.09$, $\mathrm{p}<0.001)$. These findings suggest that while infants in the IEG households showed lower exposure levels compared to DEG households, they were not completely protected from secondhand smoke exposure.

\section{Hair nicotine and cotinine}

We observed a correlation of $r=0.81 \quad(\mathrm{t}(34)=66.9$, $\mathrm{p}<0.001)$ between $\log$ transformed nicotine and cotinine levels in hair. Hair nicotine and cotinine levels among children in the NEG households were $.53 \mathrm{ng} / \mathrm{mg}$ and $0.08 \mathrm{ng} / \mathrm{mg}$, respectively. In comparison, hair nicotine and cotinine levels of infants in the IEG households were more than five times higher at $2.65 \mathrm{ng} / \mathrm{mg}$ and $0.52 \mathrm{ng} / \mathrm{mg}$, respectively. Infants in the DEG households showed nicotine and cotinine levels approximately twice as high as those in the IEG households at $5.95 \mathrm{ng} / \mathrm{mg}$ and $1.05 \mathrm{ng} / \mathrm{mg}$.

Tobit regression analyses revealed significant differences in infant hair cotinine levels between NEG and IEG (C1) and between IEG and DEG (C2) (that is, $\chi^{2}(2)=21.55$, $\mathrm{p}<0.001 ; \mathrm{Cl}: \mathrm{t}(33)=4.70, \mathrm{p}<0.001 ; \mathrm{C} 2: \mathrm{t}(33)=4.48$, $\mathrm{p}<0.001)$. The same group differences were found for hair nicotine levels (that is, $\chi^{2}(2)=25.40, \mathrm{p}<0.001 ; \mathrm{Cl}$ : $\mathrm{t}(33)=5.44, \mathrm{p}<0.001 ; \mathrm{C} 2: \mathrm{t}(33)=4.77, \mathrm{p}<0.001)$. These findings indicate again that infants in the IEG households were not protected from secondhand smoke exposure.

\section{Exploring the contribution of air, dust, surface, and finger contamination to overall exposure}

Our findings showed that infants in the IEG and DEG groups live in homes with ETS contaminated air, dust, and surfaces. To explore how air, dust, and surface contamination in living rooms and bedrooms may contribute to the overall exposure to ETS, we first examined their bivariate relations. Air and surface nicotine showed consistently positive and medium to large correlations, ranging from 0.85 (living room and bedroom surface nicotine) and 0.84 (living room and bedroom air nicotine) to 0.49 (living room air and living room surface) and 0.51 (living room surface and bedroom air). In contrast, dust nicotine levels showed low to medium correlations $(<0.40)$ with other air and surface nicotine levels.

We examined next the extent to which air, dust, and surface nicotine levels in living rooms and bedrooms predicted average urine cotinine levels. In the subset of 27 households for which measures on all variables were available, living room and bedroom surface nicotine $(\mathrm{t}(21)=-2.16, \mathrm{p}=0.043 ; \mathrm{t}(21)=3.12, \mathrm{p}=0.005)$, living room and bedroom dust nicotine $(\mathrm{t}(21)=-2.22$, $\mathrm{p}=0.038 ; \mathrm{t}(21)=2.07, \mathrm{p}=0.050)$, and bedroom air nicotine $(\mathrm{t}(21)=3.47, \mathrm{p}=0.002)$ each accounted for $\mathrm{a}$ significant proportion of variance for a total $R^{2}=0.78$ $(\mathrm{F}(5,21)=34.98, \mathrm{p}<0.001)$.

A similar model was fit in the larger subset of 41 households for which data were available on urine cotinine, air and surface nicotine in living rooms and bedrooms. In this sample, living room air nicotine $(\mathrm{t}(38)=4.62, \mathrm{p}<0.001$; semi-partial $r^{2}=0.23$ ) and bedroom surface nicotine $\left(\mathrm{t}(38)=2.38, \mathrm{p}=0.022\right.$; semi-partial $\left.r^{2}=0.06\right)$ accounted for significant proportions of variance for a total $R^{2}=0.74$ $(\mathrm{F}(2,38)=45.57, \mathrm{p}<0.001)$.

\section{DISCUSSION}

This study investigated air, dust, surfaces, and mother's index fingers to determine whether they are contaminated with nicotine, the single best marker of ETS and its chemical constituents. Nicotine was detected in the living and bedroom air of infants in the non-smoker and smoker households. Nicotine was also detected in dust and on surfaces of living rooms and bedrooms of infants in IEG and DEG households. Moreover, nicotine was detected on the index fingers of smoking mothers. Although IEG and DEG households had about the same amount of dust, we found three times as much nicotine per square metre in the living rooms of DEG than in IEG households, and we found about six times as much nicotine per square metre in the bedrooms of DEG and IEG households. That is, differences in amount of 
dust collected in the IEG and DEG households do not account for differences in dust nicotine.

Compared to non-smoker households, average contamination levels in IEG households were 5-7 times higher. Average contamination levels in DEG households were 3-8 times higher than in IEG households. As expected, nicotine contamination of mothers' index fingers was approximately the same in the DEG and IEG households. This is consistent with the observation that mothers in the IEG and DEG groups had approximately equal smoking rates. Consistent with the different levels of contamination, infants in IEG households showed exposure levels 5-8 times higher than those of infants in NEG households. Exposure levels were 2-6 times higher in infants of DEG households than those in IEG households.

\section{Multiple sources of exposure}

Infants of smokers live in homes that are contaminated with ETS and are exposed to ETS. This study showed that ETS contamination is not limited to the indoor air, but includes surfaces and dust in living rooms and bedrooms ${ }^{81328}$ and on smokers' skin. This puts infants at risk of exposure to the toxics components of ETS through multiple sources and multiple pathways, including the inhalation of contaminated air, the inhalation and ingestion of dust, ingestion and skin contact with contaminated household surfaces, and the skin of smokers.

This study provided preliminary evidence in support of the multiple exposure risk in infants. Our findings suggest that nicotine contamination of air, dust, and surfaces in living rooms and bedrooms independently account for variance in infants' urine cotinine levels. Specifically, higher levels of bedroom air, dust, and surface contamination are associated with higher levels of urine cotinine.

\section{Protecting infants from ETS exposure}

This study suggests that smokers can reduce household contamination and ETS exposure of their infants by implementing a strict smoking ban in the home and by not smoking in the proximity of the infant outside the home. These findings differ from those reported by Al-Delaimy et al $^{29}$ with respect to hair nicotine, who found no significant effect on hair nicotine levels of children (aged 3 months to 10 years) if household members smoked outside or inside the home. The fact that our sample consisted of infants under 12 months (mean 7 months) may partly explain why we found differences in exposure levels between infants in households with and without indoor smoking bans. Because Al-Delaimy et al's study ${ }^{29}$ did not include measures of ETS contamination, it is unclear whether households with and without indoor smoking bans actually differed in ETS contamination of air, dust, and surfaces. Moreover, it is unclear the extent to which ETS exposure outside the home may have contributed to the overall exposure of children in their study.

Although smoking bans appear to reduce indoor ETS contamination and ETS exposure of infants, smokers will find it difficult-if not impossible - to protect their children from ETS and its toxics components. These findings are consistent with those of Al-Delaimy et al. ${ }^{29}$ While parents in the IEG households were successful in reducing dust, surface, and air contamination and exposure levels compared to DEG households, they were unable to reduce ETS contamination and exposure to levels found in non-smoker households. Moreover, skin contamination did not differ between mothers in the DEG and IEG households as is expected because smoking rates were similar in the two groups.
To better understand the challenge to protect children of smokers from secondhand smoke, it is important to consider the parents' efforts to do so. Almost $90 \%$ of parents in the IEG households always or almost always smoked outside, and approximately two thirds always or almost always closed doors and windows when smoking outside. In only four IEG households were any cigarettes reportedly smoked indoors during the study period. The average number of cigarettes reportedly smoked in the proximity of the infants in IEG households (for example, at home, in the car, or outside when child was present) was less than 0.1 per day. It appears that parents tried their best to protect their children from tobacco smoke and had reason to believe that they succeeded in doing so. While parents were able to lower ETS contamination and ETS exposure, these efforts were insufficient to achieve levels of nicotine contamination in the homes and exposure found in infants of non-smoking parents.

Our findings point to some of the sources of ETS exposure that parents cannot easily control through indoor smoking bans. ETS can remain in the home even if smoking took place days, weeks and months earlier ${ }^{1} 1030$ through contaminated dust and surfaces, including the frame of an infant's bed and a smoker's finger. Additionally, ETS may find its way into the home through windows and doors if cigarettes are smoked outside and through contaminated clothes, skin, and dust carried into the home if cigarettes were smoked elsewhere.

This line of research has many important implications for the comprehensive measurement of ETS contamination and exposure, the study of health risks, the control of secondhand smoke, and public health policies. The comprehensive assessment of secondhand smoke contamination must consider the multiple sources of exposure, including but not limited to, air, dust, surfaces, and skin. ${ }^{8}$ Because ETS is not uniformly distributed throughout a home and over time, ${ }^{28}$ different household members may be at different risk of exposure to different sources of ETS contamination and different ETS components. For example, if exposure risks in infants are the primary concern, air samples should be taken at lower heights, and objects and surfaces should be sampled with which an infant is more likely to have contact. If smoking takes place irregularly, the duration and frequency of sampling must become an important consideration. If rooms are well ventilated during smoking, highly volatile ETS compounds and ETS particles may contribute less to long term ETS contamination than other compounds. ${ }^{8}$

Little is currently known about the differential health risks associated with the inhalation or ingestion of ETS and its toxic components or the health risks associated with ETS exposure within minutes, days, or months after tobacco smoke was emitted. As a first step, research is needed to better understand the validity of nicotine as a marker of ETS in air, dust, and surfaces over the time course of ETS contamination. Next, efforts are necessary to better measure and model the cumulative effects of exposure to ETS through different contamination sources. This and other studies suggest that dose of exposure is a complex function not only of amount of secondhand smoke, timing, and duration but also of different sources and routes of exposure.

Findings of this study suggest that interventions and public policies to reduce secondhand smoke exposure may have to be revised. ${ }^{31}{ }^{32}$ There are three major concerns. First, smoking outdoors, in different rooms, or when non-smokers are absent does not completely protect non-smokers from tobacco smoke, although it significantly reduces the likely level of exposure. Thus, children of smokers, non-smoking staff cleaning designated smoking areas in hotels and restaurant, and non-smokers renting or buying cars, apartments, and houses of smokers, are at risk of secondhand 


\section{What this paper adds}

To our knowledge, this is the first study to document that surfaces, dust, and air are contaminated in homes of smokers with infants. Infants of smokers are at risk of ETS exposure in their homes through dust, surfaces, and air. Smoking outside the home and away from the infant reduces but does not protect a smoker's home from ETS contamination and a smoker's infant from ETS exposure.

smoke exposure and the associated health risks. Second, because ETS contaminates surfaces, dust, and skin, serious consideration should be given to efforts necessary to decontaminate homes, cars, furniture, etc, of smokers. Third, because contaminated indoor environments may present significant health risks to unsuspecting non-smokers, public policies may be needed, requiring disclosure of the smoking status of former tenants of apartments and offices and/or owners of cars and homes. To understand and evaluate the health risks associated with ETS exposure, we must take into account the complex physical and chemical properties of ETS, the extent and persistence of ETS contamination of residential environments, the multiple exposure pathways, the cumulative effects of ETS exposure, and the differential vulnerability of risk populations. There is yet much to be learned before we know how to comprehensively assess the risks of ETS exposure and effectively protect non-smokers from ETS.

\section{ACKNOWLEDGEMENTS}

This study was supported by grant 7IT-0087 from the Tobacco Related Disease Research Program (TRDRP) and by the United States Centers for Disease Control.

\section{Authors' affiliations}

G E Matt, J Floro, M Garcia, Department of Psychology, San Diego State University, San Diego, California, USA

P J E Quintana, M F Hovell, N Novianti, T Juarez, Graduate School of Public Health, San Diego State University

J T Bernert, S Song, US Centers for Disease Control, Atlanta, Georgia, USA

C Gehrman, SDSU/UCSD Joint Doctoral Program in Clinical

Psychology, San Diego

S Larson, San Diego State University Foundation, WIC Program, San Diego

\section{REFERENCES}

1 California Environmental Protection Agency. Health effects of exposure to environmental tobacco smoke: final report. Sacramento, CA: The Office of Environmental Health Hazard Assessment, 1997.

2 National Research Council. Committee on Passive Smoking. Environmental tobacco smoke: measuring exposures and assessing health effects. Washington DC: National Academy Press, 1986.

3 US Department of Health and Human Services. The health consequences of involuntary smoking. A report of the Surgeon General, 1986. Rockville, Maryland: Public Health Service, Centers for Disease Control, 1986. (DHHS Publication No (CDC) 87-8398.)

4 U.S. Environmental Protection Agency. Respiratory health effects of passive smoking: lung cancer and other disorders, Vol 4. Washington, DC: US
Department of Health and Human Services, US Environmental Protection Agency, 1993.

5 Pierce JP, Gilpin EA, Emery SL, et al. Tobacco control in California: who's winning the war? An Evaluation of the Tobacco Control Program, 19891996. La Jolla, California: University of California, San Diego, 1998.

6 Pirkle JL, Flegal KM, Bernert JT, et al. Exposure of the US population to environmental tobacco smoke: the Third National Health and Nutrition Examination Survey, 1988 to 1991. JAMA 1996;275:1233-40.

7 US Centers for Disease Control and Prevention. State-specific prevalence of current cigarette smoking among adults, and policies and attitudes about secondhand smoke-United States, 2000. JAMA 2002;287:309-10.

8 Daisey JM. Tracers for assessing exposure to environmental tobacco smoke: what are they tracing? Environ Health Perspect May 1999; 107(suppl 2):319-27.

9 Cohen D, Arai SF, Brain JD. Smoking impairs long-term dust clearance from the lung. Science May 41979;204(4392):514-17.

10 Vaughan WM, Hammond SK. Impact of "designated smoking area" policy on nicotine vapor and particle concentrations in a modern office building. J Air Waste Manage Assoc 1990:40:1012-17.

11 Roberts JW, Dickey P. Exposure of children to pollutants in house dust and indoor air. Rev Environ Contam Toxicol 1995; 143:59-78.

12 Tulve NS, Suggs JC, McCurdy T, et al. Frequency of mouthing behavior in young children. J Expo Anal Environ Epidemiol 2002;12:259-64.

13 Hein HO, Suadicani P, Skov P, et al. Indoor dust exposure: an unnoticed aspect of involuntary smoking. Arch Environ Health 1991;46:98-101.

14 Matt GE, Hovell MF, Zakarian JM, et al. Measuring secondhand smoke exposure in babies: the reliability and validity of mother reports in a sample of low-income families. Health Psychol 2000;19:232-41.

15 Matt GE, Wahlgren DR, Hovell MF, et al. Measuring environmental tobacco smoke exposure in infants and young children through urine cotinine and memory-based parental reports: empirical findings and discussion. Tobacco Control 1999;8:282-9.

16 Hammond SK, Leaderer BP. A diffusion monitor to measure exposure to passive smoking. Environmental Science \& Technology 1987;21:494-7.

17 Hovell MF, Zakarian JM, Matt GE, et al. Effect of counselling mothers on their children's exposure to environmental tobacco smoke: randomised controlled trial. BMJ 2000;321:337-42.

18 Murray DM, O'Connell CM, Schmid LA, et al. The validity of smoking selfreports by adolescents: a reexamination of the bogus pipeline procedure. Addict Behav 1987; 12:7-15.

19 Song S, Quintana PJE, Matt GE, et al. GC-MS measurement of nicotine and cotinine in indoor dust. Paper presented at: 47th Annual ASMS Conference on Mass Spectrometry adn Allied Topics. Dallas, Texas, 1999

20 Bernert JT Jr, Turner WE, Pirkle JL, et al. Development and validation of sensitive method for determination of serum cotinine in smokers and nonsmokers by liquid chromatography/atmospheric pressure ionization tandem mass spectrometry. Clin Chem 1997;43:2281-91.

21 Al-Delaimy WK. Hair as a biomarker for exposure to tobacco smoke. Tobacco Control Sep 2002;11:176-82.

22 Al-Delaimy WK Crane J, Woodward A. Is the hair nicotine level a more accurate biomarker of environmental tobacco smoke exposure than urine cotinine? J Epidemiol Community Health 2002;56:66-71.

23 Klein J, Koren G. Hair analysis - a biological marker for passive smoking in pregnancy and childhood. Hum Exp Toxicol Apr 1999;18:279-82.

24 StataCorp. Stata statistical software: Release 7.0. College Station, Texas: Stata Corporation, 2001.

25 SPSS Inc. SPSS for Windows. Release 11.0. Chicago, Illinois: SPSS Inc, 2002.

26 Johnston J, DiNardo J. Econometric models. New York: McGraw-Hill, 1997.

27 Hamilton LC. Regression with graphics. A second course in applied statistics. Belmont, California: Duxbury, 1991.

28 Lofroth G. Environmental tobacco smoke: multicomponent analysis and room to-room distribution in homes. Tobacco Control 1993;2:222-5.

29 Al-Delaimy WK, Crane J, Woodward A. Passive smoking in children: effect of avoidance strategies, at home as measured by hair nicotine levels. Arch Environ Health 2001;56:117-22.

30 Daisey JM, Mahanama KR, Hodgson AT. Toxic volatile organic compounds in simulated environmental tobacco smoke: emission factors for exposure assessment. J Expo Anal Environ Epidemiol 1998;8:313-34.

31 Ashley MJ, Ferrence R. Reducing children's exposure to environmental tobacco smoke in homes: issues and strategies. Tobacco Control 1998;7:61-5.

32 Hovell MF, Zakarian JM, Wahlgren DR, et al. Reducing children's exposure to environmental tobacco smoke: the empirical evidence and directions for future research. Tobacco Control 2000;9(suppl II):ii40-7. 